\title{
Theoretical approach of branding from a semiotic perspective
}

$$
\mid
$$

Paloma Sanz-Marcos

University of Seville. Spain.

palomasanz@us.es

ORCID: http://orcid.org/0000-0002-6103-6993

DOI: http://dx.doi.org/10.12795/IROCAMM.2018.i1.07

\begin{abstract}
This paper outlines the importance of the world of signs and symbols relating to brand management. We will explore the traditional semiotics authors and how those have been influenced other academics who have researched branding from a semiotic perception. This research provides a literature revision theoretical of the brand from a semiotic insight considering its theoretical framework and the implementations of some of the analysis models for a deep revision of the implications of semiotics in branding.
\end{abstract}

Keywords: semiotics, branding, signs, meanings, marketing.
Resumen: Este artículo describe la importancia del mundo de los signos y símbolos relacionados con la gestión de marca. Exploraremos los autores semióticos tradicionales y cómo estos han influenciado a otros académicos que han investigado la marca desde una percepción semiótica. Esta investigación proporciona una revisión de la literatura teórica de la marca desde una perspectiva semiótica considerando su marco teórico y la implementación de algunos de los modelos de análisis para una revisión profunda de sus implicaciones en relación a la marca.

Keywords: semiótica, marca, signos, significados, marketing. 


\section{The symbolic approach to branding}

Semiotics can be understood as the study of signs and the function that they fulfill relating to meaning (cfr. Batey, 2013: 133). Following Mick, semioticians are concerned with analyzing the nature of meaning and the process by which the reality of words, gestures, myths and products, make sense (cfr. 1986: 197). To this end, he adds that semiotics, far from being a method or a science, is considered a doctrine that incorporates a broad set of concepts, principles and tools whose objective is to explain communication and meaning (cfr. Mick, 1997: 256-258). In addition, Eco highlights the importance of this discipline in society affirming that humanity is established when society is established, but society is conventional when there is trade in signs (cfr. 1994: 107). Semiotics is about an area of knowledge that has traditionally been linked to the field of communication, and more specifically, to advertising. However, along the main objectives of our work, it is not contemplated to carry out an exhaustive study of the implications of semiotics in the communicative aspect, that is why we will stop only in what our object of study, that is, branding.

Following Mick, who carries out a thoroughly review about branding under the semiotic perspective, researchers have avoided addressing brand management from a detailed and systematic point of view (cfr. 1986: 201). In this sense, he adds that there is a tendency to link semiotics with all kinds of studies that relate meaning and marketing without a reasonable discussion that distinguishes between what particular currents or semiotic concepts these evaluations are based on (cfr. Mick, 1997: 258). That is why in order to address such issues in the most reliable possible way, it is necessary to outline those academics that have been dealing with this discipline at first and, consequently, influence the subsequent theories that will develop the advancement of our work. We are referring to Ferdinand de Saussure and Charles Sanders Peirce, whose posthumous works contributed with important contributions. Known as the father of modern linguistics, Saussure, was the first to systematize his views on language as an example of a system of signs (cfr. Batey, 2013:139). Through his seminal work Cours de linguistique générale (1916), the author offers a structuralist vision of the language that goes through studying the nature and relationships of linguistic signs. Focused on the linguistic system per se, his work is not concerned with conducting a study about the connections between this system and other elements such as the sociocultural context (cfr. Batey, 2013:139). Its fundamental contribution is based on the dyadic relationship established between sign 
and signifier, offering therefore a relational perspective of the language that analyzes the relationships and interactions between words and the meaning that derives from them (cfr. Mick, 1986: 197). Saussure argues that the bond that unites signifier with meaning is arbitrary, so there is no connection with reality (cfr. Saussure, 1916: 103). In this sense, it is not until Peirce develops his theories around the figure of the interpreter, that the context in the development of this discipline is studied implicitly. Similarly to Saussure, Peirce studies the relationship between meaning and significant, with the particularity that introduces the study of the sign from a point of view where he consider as triadic in which he incorporates the figure of such interpreter. This peculiarity underscores the importance of the social and the culture in the interpretation of meanings, provoking what Mertz points out as an opening towards an analysis that "includes but moves beyond language [that] pushes scholars to integrate issues of social context more systematically into the analysis of meaning" (Mertz, 2007: 338). Starting from these advances, Morris, expands these contributions offering what has been a distinguished approach of these previous scholars, that is, a pragmatic perspective. Considering Mick, although Morris understands that Saussure's contributions offers a syntactic approach and Peirce's offers a semantic orientation, Morris's advances lies in his contribution towards a pragmatic approach to semiotics, that is, the study of how signs are used and interpreted, in terms of relevance, consensus, etc. (cfr. 1986: 200).

Currently, there are numerous authors who, from these classical disciplines, have shaped their own theories around the study of meaning providing an optimal starting point for the advancement of our work in communicative matters. It is the case of Barthes who has been recognized as one of the most influential authors in semiotic advertising reflection (cfr. Pérez Tornero, 1982: 13; Mick, 1986: 201; Batey, 2013:139). In the opinion of Rodríguez \& Mora, the author stand up for a social and human sciences interested in that factory of socially relevant signs that is advertising (cfr. 2002: 22). One of the most noted contributions of Barthes is his contribution about considering that communication disciplines such as advertising has to be considered as the elevation of a scientific object on which to apply an analytical methodology (cfr. Rodríguez y Mora, 2002: 23). In works such as Mitologías [Mythologies] (1991) or Rhétorique l'image [Rhetoric of the image], originally published in 1964, Barthes open up the advertising semiotics that, as we will have the opportunity to analyze later, will affect the semiotic models of branding. Influenced by Saussure, Barthes states that it is known that every message is the union of a level of expression or signifier and a level of content, or meaning (cfr. 1993: 239). In this way, the author alludes to the fact that the signifier is the physical medium through 
which the meaning is transmitted, understanding it as the mental representation of that signifier. In this context, he maintains that Saussure's model focuses on denotation and does not contemplate connotation. That is why, in order to restore a certain balance, the author exposes his theory about the connotative dimension of meaning. Barthes proposes a model of construction of meaning based on the different orders of meaning where, at a first level of significance, the "denotation" stands out and on a second level, the "connotation". Under this premise, it advances that a photograph provides a denoted meaning (first order) and the meanings of that photograph, fruit of human intervention, correspond to the connoted meanings (second order) (cfr. Batey, 2013: 140). Based on this premise, Barthes distinguishes between three types of messages in advertisements, namely, the linguistic message provided by the text, the literal message, related to the denotation and the symbolic associated with the connotation. In Rhétorique l'image, exemplifies this model through the analysis of the Panzani food brand. In this case, the linguistic message is constituted by the brand (Panzani) and the slogan Pates-Sauces-Parmesan a l'italienne de luxe. The literal message is made up of the elements that appear in the advertisement scene such as the brand's foods and products. And the symbolic type is shown through a shopping basket and would come to represent the traditional (cfr. Madrid Cánovas, 2005: 210-211). On the other hand, Batey expresses that the denotation supports a literal meaning, while the connotation is what is implicit in a word besides its literal meaning, so that the connotative meaning is more variable, figurative and subjective and includes the feelings and emotions that generate a word in people as well as sociocultural and personal associations that arise from the race, social class, gender, religion, etc., of that subject (cfr. 2013:138). Under this perspective, the connotative meaning is unfailingly enriched by the associations and feelings that are attributed to them from the literal or denotative. In this sense, the work of Barthes, comes to support our object of study insofar as it contemplates those orders of significance that have to do with the consumer, that is, the reflection of their cultural context or their values (cfr. Batey, 2013: 143). Also, given that the author conceives of all images as polysemic (cfr. Madrid Cánovas, 2005: 211), considers that the functions of the linguistic message with respect to the image can be anchoring and relaying. Regarding the anchoring, the author defines it as a floating chain of meanings (cfr. Barthes, 1964: 44), and advances that the anchoring is a control, holds a responsibility -in front of the projective power of the figures- about the use of the message; in relation to the freedom of the meanings of the image, the text has a repressive value (cfr. Barthes, 1964: 44-45). As for the relay, it is associated with aspects of popular culture such as comics, or television. In this case, 
the image is conceived as semiotic accompaniment. Barthes argues that the word relay reaches a great importance in the cinema, where the dialogue does not have a simply elucidatory function, but actually contributes to move the action forward (cfr. 1986: 37). In short, the projection of Barthes is evident in later works by authors such as Durand, Péninou or Bonsiepe. This is what Pérez Tornero recognizes when he says that the Barthian gesture will have a singular repercussion: it will create tradition, and there will be a lot of what will work on the problems raised by Rhéthorique de l'image (cfr. 1982: 16). In this context, Eco generates a model of advertising analysis that, starting from Barthes, becomes a testing ground for visual semiotic methodology (Madrid Cánovas, 2005: 217). His research starts by highlighting the possibilities of visual codes analyzing the relationship between two different registers: verbal communication and visual communication (see Echo, 1986: 233). Among its purposes, Eco emphasizes that this preliminary verification allows us to examine again the topic of the relations between rhetoric and ideology (cfr.1986: 229). For the purposes of visual communication, it identifies several levels of coding, namely, the iconic, iconographic, tropological, topic and enthymematic level (cfr. Eco, 1986: 233-236). In this sense, we fully agree with Madrid Cánovas when he argues that the analysis that accompany this theory hardly offer a systematic exploitation of the model, since they are made taking as isolated examples of figures and visual rhetorical arguments that perfectly demonstrate the hypothesis raised by Eco, that is, the bidirectional relationship between ideology and rhetoric (cfr. 2005: 219). In fact, as Eco himself states perhaps it would be convenient to realize that advertising has no informative value. Although its limits are not in the possibility of a persuasive reasoning but in the economic conditions that regulate the existence of the advertising message (cfr. 1986: 250).

That is why, in order to enrich our study, we will offer those semiotic models that consider the strength of the advertising activity as a creator of meanings. In effect, our work is framed around those branding models that deal with the management of meanings - especially cultural ones-as they consider those intangible aspects that are manifested through the brand. In this sense, the brand interacts with various groups of consumers with whom it relates. In this line, authors like Eguizábal, the products stop being objects to become signs. And, as a corollary, what is consumed are not goods, they are meanings (cfr. 2007: 127). Although, the products surpass their utilitarian character and brands are considered like agents bearers of meaning, we can consider brand like an absolute sign because it covers all the indicative functions imaginable (cfr. Sánchez Corral, 1997: 162). The brand, from a semiotic point of view, is understood as a sign that fills with meaning. What makes the brand 
meaningful, warns Costa, are its attributes of value, the connotations and the saturation of meaning, elements of semiotics (cfr. 1992: 45).

Similarly, Semprini considers the role of subjects with respect to brand meanings when he states that the brand is made up of the set of discourses held by all the subjects (individual or collective) that participate in its genesis (cfr. 1995: 47). In this line, Costa's vision seems illustrative because it considers the perceptions of individuals, as reasons dependent on the meanings of the brand. It is observed that these perceptions compromise the purchasing decision of the subjects who use expressions of the type "I do not see myself with this product" or "this brand is not for me" showing this idea (cfr. 2004: 111). In effect, the brand has the ability to confer meaning in cultural environments that are fedback into what Semprini compares with a semiotic engine: brands fuel is composed of elements as disparate as names, colors, objects, dreams, desires, etc .; the result (if the engine has been properly run) is an orderly, structured, interpretable world, and, in a certain sense, attractive (cfr. 1995: 47).

Rodríguez \& Mora add that advertising is not a discourse endowed with specificity, but that it is open to social semiosis. In this way, it must be understood as a juxtaposition or mixture of signs, texts, registers, codes, etc., so they advance that, it must be studied without separating it from the fabric of culture extrapolating what it takes and what it contributes (cfr. 2002: 13-19). In this line, other semiologists like Danesi affirm that the study of semiotics around branding is something purely social:

It «reifies» the product, service, or company inserting it as an element in the web of meanings that constitute a culture - «reification» is the term used in philosophy referring to the actualizing of something that is conceptual in real ways $-[\ldots]$. Brands have, in effect, been anthropomorphically transformed into personalities with identities that have become merged with those of consumers. One feeds off other (2006: 33)

From this perspective, Rosenbaum-Elliot, Percy and Pervan, combine the mechanisms of semiotics with other disciplines such as psychology to emphasize the importance of the social. Concepts such as self-concept, say the authors, are offered as a set of meanings that must be managed:

We live in a symbol-rich environment and the meaning attached to any situation or object is determined by the interpretation of these symbols. Through the socialization process we learn not only to agree on the shared meanings of some symbols but also to develop individual symbolic interpretations of our own. We use these symbolic 
meanings to construct, maintain, and express each of our multiple identities (Rosenbaum-Elliot, Percy y Pervan, 2011: 50).

\section{Analyzing Brand Semiotic Models}

Regarding the types of semiotic models applied to the management of brand meanings, we highlight authors such as Floch or the aforementioned Semprini whose postulates offer an advance towards the importance of semiology in brand communication. In this sense, Floch's vision recognizes the generative quality of meaning by the brand offering a meeting point between the study of the brand and the semiotics. Based on demonstrating the usefulness of the semiotic approach in marketing communication, Floch's model focuses on the analysis of the so-called objects of meaning, whose importance stands out as being the only realities of which semiotics deals and wants to take care (cfr. 1993: 23). From this analysis, the absence of taking into consideration the context in its model is revealed. In this sense he states that semiotics, adopts a clear position by delimiting its field of research. It does not deny the existence of a context but argues that it should not intervene unless if this context is approached as if it were a text. If the context is an assortment of data and annotations and diverse, it is not the object of semiotics (cfr. Floch, 1993: 22). Floch, understands that for semiotics to integrate the context in their study, it is necessary that it be considered as text, that is, as an object of meaning. That is why he later considers that semiotics has to be complemented with the intervention of other disciplines (cfr. Floch, 1993: 22).

In spite of what has been said, it carries out a deep systematization around the brand meanings that, as Chevalier \& Mazzalovo affirm became common among the advertisers, the specialists in brand management and the coolhunters (cfr. 2005: 136). This systematization, the author points out, represents a real added value in three major types of production or transformation: when it is necessary to obtain more intelligibility, more relevance and more differentiation (cfr. Floch, 1993: 26). In terms of intelligibility, the author understands that the semiotic approach can make possible to see more clearly the nebula of meaning of what advertising concepts are or end up (cfr. Floch, 1993: 26). In this way, semiotics are considered as an explanatory force for the advertising provided by this intelligibility by choosing a concept, by recovering it or by confronting it with those of the competition (cfr. Floch, 1993: 26). Relevance, Floch points out, can produce this second type of added value because it is dedicated to distinguishing and ranking a certain number of 
homogeneous levels of description (cfr. 1993: 28). It is a tool that allows advertisers to choose or retain those qualities of form, color or volume that are relevant and, ultimately, ensure that packagings, design products or the logo mean what they have to mean (cfr. Floch, 1993: 29). Regarding differentiation, Floch points out that it consists in showing things, or rather postures, different, complementary and others that are different and contradictory (cfr. 1993: 30). In this sense, semiotics is considered an efficient instrument for constituting the nature and relationships of similarities and differences in communication semiotics. This is the origin of the semiotic square. This is also the world of semiotics, where it intervenes in marketing and communication. The work and competence of semiotics consist of moving from the understanding of differences to the definition of relationships. And, to do this, semiotics has had to distinguish and prioritize a certain number of levels beforehand, in order to be able to arrange its network of relationships on a homogeneous level (cfr. Floch, 1993: 30).

Starting from this premise, he develops his semiotic square by which he constructs a typology of the possible forms to which advertising communication resorts to valorize the objects that he must advertise (cfr. Madrid Cánovas, 2005: 232). This model, goes by establishing links between the three principles that we have exposed previously from the relationships and operations of two fundamental values: existential and utilitarian. Following Chevalier \& Mazzolovo they argue that the two main typologies (utilitarian values/existential values) presented in his model show the narrative semiotics, which distinguishes in a narrative, the base values (existential, mythical utopian) of the utilization values (utilitarian or practical) (cfr. 2005: 138).

So, on the one hand, the "existential values" correspond to the great conceptions of the existence of man, as opposed to the "utilitarian" that are secondary and material. On the other hand, the semantic axis on which these values are based, is also composed, by two opposites: "practical / utopian". In the same way that their negatives, the "non-utilitarian" and the "non-existential" respond to the opposite "critical / playful aesthetic". All in all, Floch performs a network of direct and indirect relationships by placing the concepts that correspond to each other on both sides of the table. On the left side, it places the "utilitarian" and "non-existential": "practice / criticism"; and in the right the "existential" and "non-utilitarian": "utopic / ludic aesthetic" Floch, believes that these mechanisms are reflected in the construction of the meaning of the brand, because, through it, the advertising identifies the consumption values of the public and can define their communication relationship with 
the recipients.

\section{Graphic 1. Floch's Semiotic model}

\section{UTILITARIAN VALUES}

EXISTENTIAL VALUES

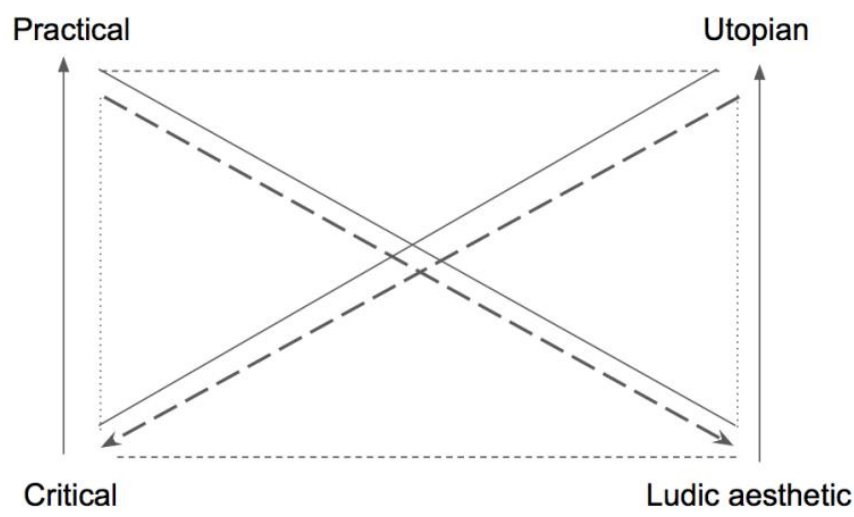

NON-EXISTENTIAL VALUES

NON-UTILITARIAN VALUES

From: the author considering Floch (1993.

In short, Floch's proposal is a success to investigate with semiotic tools the significant procedures of advertising (cfr. Madrid Cánovas, 2005: 240). Under Floch's vision semiotics would then facilitate a certain power in the structuring, organization and explanation of the stakes that can be conceived from the moment in which the product, service or behavior, are addressed as something significant (cfr. Floch, 1993: 26). The author manages to propose a semiotic model applicable to branding that, as we will see later, will influence the construction of models by other authors such as Semprini (cfr. Chevalier \& Mazzolovo, 2005: 145).

However, the researcher's approach does not comply with the dynamic of what it takes brand management. Let's say that the absence of "context" in the Floch model that we previously pointed out, is equivalent to contemplating the brand as a static and fixed asset that does not understand its evolution. This statement lead us to 
consider the adequacy of other models that explicitly contemplate the sociocultural context that irremediably affects the management of brands.

\subsection{Semprini's Semiotic mapping of consumer values}

For the purpose of considering this sociocultural aspect, we will also address Semprini's "Semiotic mapping of consumer values". Part of the special significance of this model is that Semprini understands the brand as an active element that generates meanings. Semprini, materializes his model through a two-dimensional plane, which unlike the representation of a painting offers a spatial continuity in which each element holds a position in relation to the position of other elements present in the mapping (cfr. 1995: 108). From this composition, the incipient interest of the author to introduce the context as a basic component in the semiotic analysis of the brand emerges. Determined by four positions, the importance of the context is evidenced in the study of the connections between the components that form it and that, in turn, always depend on each other, on the disposition and relation of other previous elements. Also, the author adds that mapping allows us to analyze very different situations in the field of marketing: from the evolution of a brand over time or the positioning of brands in a segment of the market to the expression of a marketing problem that overcomes the barriers of a segment and a product (cfr. Semprini, 1995: 109).

Semprini understands that his model reflects the impact it has for a brand by positioning it in one or another quadrant of the mapping. Starting from Floch, it uses four fundamental terms that define it, namely, "practical valorization", "utopian valorization", "critical valorization" and "ludic valorization". In this sense, he conceives of values as underlying tendencies of a significant number of individuals in a given society and at a given moment about what is preferable, desirable or expected (cfr. Semprini, 1995: 108). Semprini places these values in two perpendicular axes, facing each other on the vertical axis: practical and utopian value, and horizontal, critical and practical value. As for "practical valorization", it considers the values of use and is based on the concrete and utilitarian purpose of the product, focusing on those measurable and objective characteristics. The utopian valorization is linked to the base values and is based on subjective and contextual variables. Let's say it points to values oriented to achieve goals towards the future, projects to be carried out. In this 
regard, the author points out that, while the "practical" and the "utopian" are opposite in the field of the brand, the same does not happen when we refer to the product (cfr. Semprini, 1995: 11).

Around the horizontal axis, "the critical assessment", despite being linked to the "practice", is defined from a difference that shares with it: the submission to a constant questioning based on external elements. Based on the questioning, comparison and evaluation of the coherence and credibility of the brand values, it has a great importance in shaping the sense of the brand, since through the value judgment the criteria in the that should be framed (cfr. Semprini, 1995: 112). Finally, "the playful evaluation" exploits the emotional, and a strong hedonistic character is understood.

Also, these four valuations are ordered by "geographical zones" that correspond to the four cardinal points. In this way, in the upper area of the horizontal axis, we find the north, in which the "utopian" is found, with the south being in the lower zone, equivalent to the "practical". Around the left part of the painting, corresponding to the west, there is the "critical" while in the right part belonging to the east, the "playful" is distinguished. This combination of the values of the mapping is established by superposition and not by juxtaposition, so that an element is allowed to travel vertically and horizontally through the different areas. So, making an analysis of the western area, from the pole of the utopian (north) to the practical (south), the critical distancing and the search for meaning take on very different aspects (cfr. Semprini, 1995: 115). In the northwest area we would enter in the field of the valorization of culture and, more generally, in the field of knowledge (cfr. Semprini, 1995: 114), something that undoubtedly overcomes the absence of cultural character which proposed the Floch model. As for the sense of critical appreciation is changing progressively in the west but towards the practical pole (cfr. Semprini, 1995: 116). Approaching to the south with respect to the practical pole, we find the need for understanding, the main feature of the entire western part of mapping, loses its critical dimension, becoming an operating-type rationality concerned with how products, the world or speeches (cfr. Semprini, 1995: 116). In front of this "west" part, we move towards the "east" in which the "authority" falls on the "playful" and the "emotions" characteristic of the "playful", they move from the "utopian" towards the " practical". Likewise, the horizontal axis is dynamic, so that the "utopian valorization" goes altering according to its position with respect to the "critical" pole necessary- or to the pole "Playful" -voluntary-, which marks his "individual" or "collective" attitude (cfr. Semprini, 1995: 120). 
On the part of the south, around the "practical", it is characterized by the search for objectivity and instrumentality, which is accentuated as it approaches the "critical west" in which the technical function is distinguished. However, when approaching the "playful east", the practical value is losing its more functional and technical nuances to assume others, always functional, but more emotional or psychological (cfr. Semprini, 1995: 121-122). So feeling is imposed on other values giving rise to the psychological function. In this regard, Semprini adds that objects must continue to have a function and produce short-term results despite the fact that now they are pleasant results that provoke a certain euphoria (cfr. Semprini, 1995: 122). To conclude, the author points out that the fact of dividing the mapping area into quadrants facilitates its description and makes mapping, as a tool, more operational. However, we must not forget that the division of mapping prevents us from reflecting in it some nuances that only the continuity of the conceptual space can hold (cfr. Semprini, 1995: 122-123). So that in turn, divides the mapping into quadrants that involve a different conceptual nature that aims to respond to the continuous segmentation that causes the convergence of values. In the northwest quadrant, it is characterized by the notion of "mission", which highlights the character of the project and the will to transcendence (cfr. Semprini, 1995: 123). This quadrant is born from the union of the "utopian" and the "critical" and is directed towards the search for a project where notions such as necessity, will or duty prevail in the case of utopian and collective projects. Around this tendency, Semprini affirms that it is rare in the world of brands and consumer values (cfr. Semprini, 1995: 125). Relating to the northeast quadrant, it has a certain relationship with the previous one, as the "playful" and "utopian" values converge and are defined by the notion of "project". Following Semprini, what differentiates both quadrants is that while the mission is always the result of a duty, the project rests on the will that gives it the idea and gives it the energy necessary to carry it out (cfr. Semprini, 1995: 125). In this sense, it is observed that, the individual acquires greater relevance than in the quadrant of the "mission" insofar as the "playful" assessment provides a series of stimuli and emotions related to the internal exploration of the individual. In the southeast quadrant, the "playful" and "practical" valorisation is noticed. In this quadrant, there is a rejection of the sentimental manifested in the "practical" components of an objective and rational nature. However, Semprini warns that the contradiction that seems to be contained in this quadrant, at the same time practical and playful, is only superficial. Even when we are in a quadrant of productoriented culture, the technical use of the object tends to be relegated to the background after the more "psychological" connotations (cfr. 1995: 128-129). The southwest quadrant is characterized by enhancing the emotional and psychological 
components, where the "practical" and "critical" valorisation are crossed. In this, the utilitarian character is highlighted and focuses on the objective and demonstrable qualities of the product. In this quadrant, the notion of "information" acquires prominence since, the valorization of the basic and necessary and that of the advantageous is purely rational and preaches the calculation and analysis as useful to measure the value of a product (cfr. Semprini, 1995: 129).

Graphic 2. Mapping of consumption values

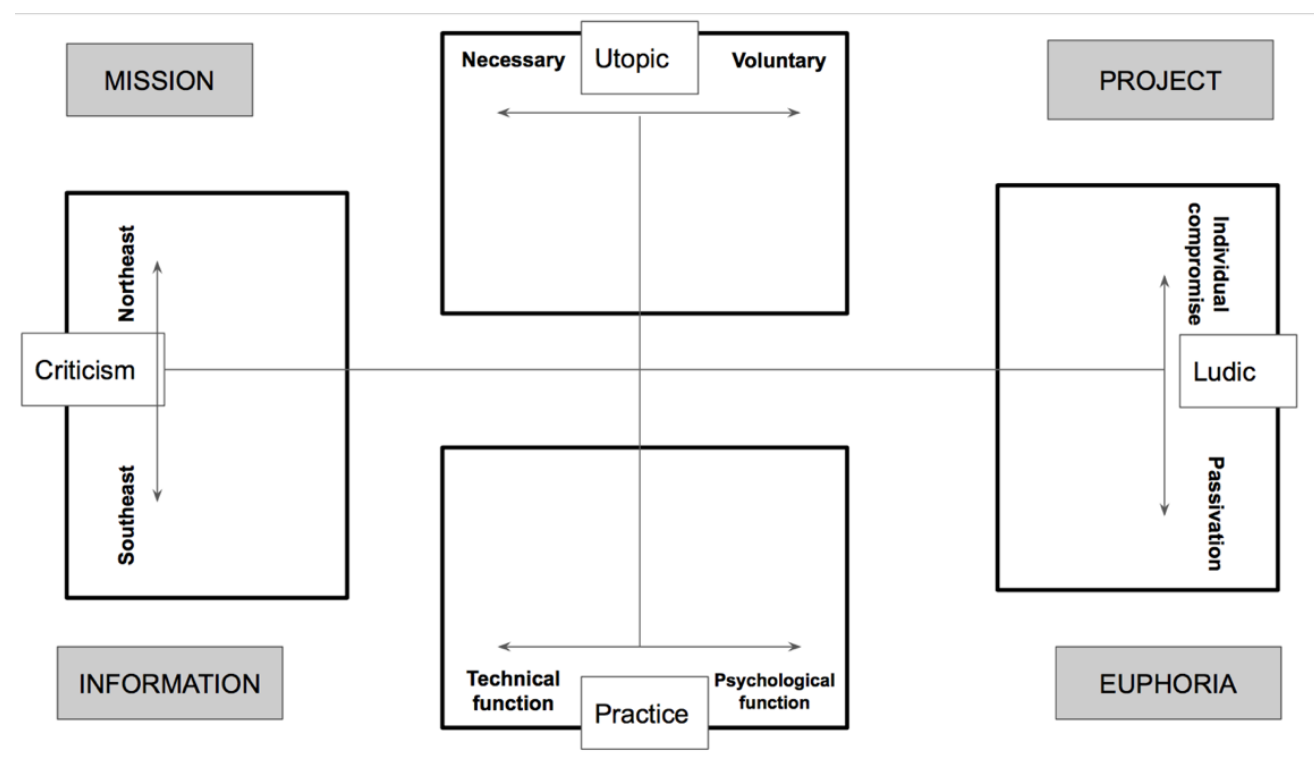

From: the author considering Semprini 1995

All in all, Semprini's mapping of consumption values offers a suitable starting point to respond to the semiotic character of the brand, starting from a dynamic vision. In this sense, it supposes an evolution of the semiotic models that authors such as Chevalier \& Mazzolovo even come to consider as a powerful, versatile instrument that is easy to apply in a real sense (cfr 2005: 148). It also includes the analysis of the context that, as we have been commenting, is of a capital nature for the brand. 
attributes or services but also as a myriad of signs that mediate between their physical reality and the perceptual spaces of consumers. The semiotic nature of brands is evident in the ability of generate meanings through signs. The branding models exposed show us that the semiotic theory can be applied to real brands in a consumer market context. It also illustrates the dynamic nature of a brand when studying their meanings. A brand can be thus defined by their signs and physical and perceptual elements that compose permanent processes of representation. Semiotic theory allows us to consider brands as a dynamic network of elements. Studying how these elements comprise representations is an important value for brand management practice.

This perspective also illustrates the dynamic nature of brands and echoes the importance for brand managers to obtain a complete view of how brands are entities able to create meanings useful for consumers.

\section{References}

BARTHES, R. (1964): "Rhétorique l'image". Communications, 4, pp. 40-51.

BARTHES, R.(1980): Mitologías. México, Siglo XXI.

BARTHES, R. (1993): La aventura semiológica. Barcelona, Paidós

BATEY, M. (2013): El significado de la marca: cómo y por qué ponemos sentido a productos y servicios. Buenos Aires, Granica.

CHEVALIER, M.y MAZZALOVO, G. (2005): Pro logo: por qué las marcas son buenas para usted. Barcelona, Belacqua de Ediciones y Publicaciones.

COSTA, J. (2004): La imagen de marca. Barcelona, Paidós.

DANESI, M. (2006): Brands. Routledge.

EGUIZÁBAL, R. (2007): Teoría de la publicidad. Madrid, Cátedra.

FLOCH, J. (1993): Semiótica, marketing y comunicación. Bajo los signos, las estrategias. Barcelona, Paidós.

MADRID CÁNOVAS, S. (2005): Semiótica del discurso publicitario : del signo a la imagen. Universidad de Murcia, Servicio de Publicaciones.

MERTZ, E. (2007): "Semiotic anthropology". Annual Review of Anthropology, 36, pp. 337-353.

MICK, D.(1986): "Consumer Research and Semiotics: Exploring the Morphology of Signs, 
Symbols, and Significance", The Journal of Consumer Research, 13(2), pp. 196-213.

PEREZ TORNERO, J. (1982): Semiótica de la publicidad. Mitre, Barcelona

RODRÍGUEZ, R. y MORA, K. (2002): Frankenstein y el cirujano plástico: una guía multimedia de semiótica de la publicidad. Universidad de Alicante.

ROSENBAUM-ELLIOT, R.; PERCY, L.; y PERVAN, S.(2011): Strategic Brand Management. New York, Oxford University Press.

SAUSSURE, F. (2002): Curso de lingüística general. Madrid, Losada.

SÁNCHEZ CORRAL, L. (1997): Semiótica de la Publicidad. Narración y discurso. Madrid: Síntesis. SEMPRINI, A. (1995): El Marketing de la Marca: Una Aproximación Semiótica. Barcelona: Ediciones Paidós. 